\title{
MULHERES NO ATLETISMO (BARBACENA-MG, 1926): UM ESTUDO PRELIMINAR
}

\author{
Igor Maciel da Silva ${ }^{1}$ \\ Sarah Teixeira Soutto Mayor ${ }^{2}$ \\ Recebido em: 21/02/2020 \\ Aprovado em: 20/04/2020
}

Resumo: O objetivo do artigo é apresentar pistas sobre a presença das mulheres de Barbacena - MG no atletismo no início do século XX. Busca responder às seguintes questões: quem foram essas mulheres, como se inseriram na prática, quais sentidos e significados de sua participação. A metodologia é a análise de fontes periódicas, em específico, o jornal Cidade de Barbacena. Como resultado preliminar, concluímos que as atletas eram as jovens da região que se inseriram na modalidade mediante o fato de serem torcedoras do time de futebol Olympic Sport Club. Os sentidos e significados remetem a um lugar secundário conferido a elas no cenário esportivo, com uma participação limitada e destacada por caracteres relacionados à estética, ainda que essa participação representasse possibilidades de enfrentamento de barreiras sociais e de emancipação.

Palavras-chave: Atletismo; Mulheres; História do esporte; História das mulheres; Barbacena - MG.

Abstract: The objective of this article is to present the attendance of women from the city of Barbacena-MG (Brasil) in athletics at the beginning at 20th century and seek to answer those following questions: who were those women. How they started the practice. And wich were the senses and meanings of their participation? The methodology was the analyses of periodic sources in newspapers in specific. As the presented results those athletes were the local young ladies who entered the modality through the fact that they are fans from the soccer team Olympic Sport Club. The senses and meanings as like the fact the citizens could have done of the reason of their participation in activities that did put them in a secondary place in relation of men denote cause and effect of their emancipation.

Keywords: Athletics; Women; Sport History; History of women; Barbacena - MG.

Resumen: El objetivo del artículo es presentar evidencias sobre la presencia de mujeres de la ciudad de Barbacena - MG en el atletismo a principios del siglo XX. Intenta contestar las siguientes preguntas: quiénes eran estas mujeres, cómo experimentaron la práctica, cuáles fueron los significados de su participación. El método de investigación fue el análisis de fuentes periódicas, en particular el periódico Cidade de Barbacena. El resultado muestra que

\footnotetext{
${ }^{1}$ Doutorando em Estudos do Lazer, Professor substituto do curso de Educação Física da Universidade Federal de Juiz de Fora, Campus Avançado Governador Valadares-MG, Brasil. E-mail: professorigormaciel@ gmail.com. ORCID: https://orcid.org/0000-0002-6560-0475. Este artigo é um fragmento revisitado da pesquisa de mestrado financiada pela CAPES, intitulada "Elas se divertem (Barbacena - MG, 1914 a 1931)" (SILVA, 2018).

${ }^{2}$ Doutora em Estudos do Lazer, Professora do Departamento de Educação Física da Universidade Federal de Juiz de Fora, Campus Avançado de Governador Valadares. E-mail: sarahsoutto@gmail.com. ORCID: https://orcid.org/0000-0003-1643-6223.
} 
las atletas eran mujeres jóvenes de la región que ingresaron al deporte porque eran hinchas del equipo de fútbol del Olympic Sport Club. Los significados muestran un lugar secundario para las mujeres en la escena deportiva, con una participación limitada y destacada por la estética, aunque esta participación podría representar posibilidades de afrontamiento de las barreras sociales y de emancipación.

Palabras clave: Atletismo; Mujeres; Historia del deporte; Historia de la mujer; Barbacena MG.

\section{Introdução}

A prática de esportes por mulheres no Brasil no início do século XX foi permeada de ambiguidades, oscilando em iniciativas de fomento e em ações inibitórias (SCHPUN, 1997; GOELLNER, 1999). Ideologias e movimentos nacionais protagonizados por educadores, intelectuais e estadistas aconselhavam atividades esportivas visando à utilidade do corpo feminino, direcionadas para a função social destinada à mulher, tais como contribuir para a gestação de filhos e filhas aptos de acordo com uma ideia eugênica de desenvolvimento da nação e, ao mesmo tempo, proporcionar e manter a graciosidade esperada para o sexo feminino (GOELLNER, 1999).

Discursos sobre o corpo feminino que infligiam mecanismos de controle às ações da mulher permearam o mundo dos esportes, reverberando na indicação e no incentivo de modalidades específicas, reconhecidas como seguras e promissoras ao desenvolvimento sadio de seu corpo. Dentre elas podem ser destacadas: tiro ao alvo, tênis, natação, basquete, atletismo e vôlei (GOELLNER, 1999, MELO, 2011, SANT'ANNA, 2014, MELO, 2019, SILVA, 2017). Por outro lado, práticas entendidas como incompatíveis com a natureza delicada das mulheres eram desestimuladas e até mesmo proibidas. Das recomendações e ações de controle pensadas desde os primórdios da prática esportiva em solo brasileiro, leis foram posteriormente criadas. Como exemplo, em determinação do Conselho Nacional de Desportos, no ano de 1941, o artigo 54 do Decreto-Lei que estabelecia as bases de organização dos esportes no país deixava claro o controle exercido sobre as possibilidades de prática esportiva das mulheres: “Às mulheres não se permitirá a prática de desportos incompatíveis com as condições de sua natureza, devendo, para este efeito, o Conselho Nacional de Desportos baixar as necessárias instruções às entidades desportivas do país” (BRASIL, 1941). Os esportes que envolviam muito contato físico ou exigiam demasiado esforço eram, assim, proibidos. Em 1965, esportes como futebol de campo, de salão e de praia; pólo; pólo aquático; rugby; halterofilismo e baseball foram explicitamente proibidos ao sexo feminino pelo mesmo Conselho, por meio da deliberação $n^{\circ}$ 7/65 (CASTELLANI 
FILHO, 1994). Nesse sentido, vale destacar a força de um discurso que não se manteve apenas nos costumes do cotidiano, mas que se materializou em forma de legislação.

Em se tratando especificamente do atletismo, vale ressaltar que nos Jogos Olímpicos de 1900, em Paris, as mulheres puderam participar da modalidade após sua ausência na primeira edição das competições, em 1896. Contudo, naquele momento essa era apenas uma prática de exibição para elas (OLIVEIRA; COSTA, 2006). Embora no Brasil a modalidade tenha sido vivenciada desde os anos finais do século XIX por ambos os sexos (MELO, 2009, MELO, 2019), foi somente em 1948, nos Jogos Olímpicos de Londres, que o país enviou brasileiras para competirem.

As pioneiras do atletismo foram Benedicta Sousa de Oliveira, nos $100 \mathrm{~m}$ e nos 4x100m; Elisabeth Clara Muller, nos 100m, no arremesso de peso, no salto em altura e nos 4x100m; Gertrud Ida Morg, no salto em distância, modalidade que estreava nesta olimpíada com o salto de $5,12 \mathrm{~m}$; Lucila Pini, nos $200 \mathrm{~m}$ e nos 4x100m; Melânia Luz, nos 200m e nos 4x100m e Helena Cardoso de Menezes, nos 100m e 200m (OLIVEIRA; COSTA, 2006, p. $8250)$.

A participação das mulheres no atletismo nos Jogos Olímpicos de 1900 enquanto prática de exibição remete a um lugar semelhante ocupado por elas em outras modalidades e circunstâncias. No caso do turfe e do futebol, por exemplo, a participação feminina era comumente associada, no início do século XX, à assistência. Isso porque se acreditava que elas abrilhantavam o ambiente de atividades voltadas, a princípio, para a destreza e a robustez dos corpos masculinos. Souza Neto (2010), ao estudar a invenção do torcer em Belo Horizonte, de 1904 a 1930, aponta que

O caráter "décor" posto na funcionalidade da presença feminina aos jogos de futebol tendia a permanecer à medida que a lógica da assistência, distanciada da paixão clubística prevalecia nos "matches" de football. Obviamente a mulher representava, assim como uma banda de música, um atrativo atrelado à ideia do espetáculo esportivo, cada vez mais intensa, ainda na ausência de pertencimento clubístico (SOUZA NETO, 2010, p. 35).

Os exemplos mencionados remetem à outra questão: a intrínseca relação entre esporte e a ideia de modernidade, tão em voga no período. Percebe-se, por meio de investigações preliminares $^{3}$, importantes relações estabelecidas entre as prerrogativas de uma modernidade almejada e o desenvolvimento do fenômeno esportivo em várias cidades brasileiras, no final do século XIX e início do século XX. A modernidade prometida pelo esporte estava relacionada a um intento de adaptação à nova vida social, produtiva e tecnológica (SEVCENKO, 1993): "para tornarem-se velozes e adaptadas às modernas fontes de energia,

\footnotetext{
${ }^{3}$ Podem ser citados os textos publicados na coletânea "Os sports e as cidades brasileiras: transição dos séculos XIX e XX”, organizada por Victor Andrade de Melo (2010).
} 
as pessoas tinham de ser fisicamente condicionadas e psicologicamente motivadas" (IDEM, 1993, p.82). A prática esportiva cumpria um importante papel na representação de uma cidade, um estado ou um país que almejavam serem vistos como modernos.

No caso de Minas Gerais, a educação de corpos masculinos e femininos afeitos aos novos preceitos que justificariam a construção da capital Belo Horizonte como a cidade moderna desejada desde o traçado de seu terreno encontrava no esporte uma de suas fortes vias de confluência (SOUTTO MAYOR, 2017). De forma semelhante, discursos que destinavam funções sociais diferentes para homens e mulheres estiveram presentes na vida esportiva de outras cidades do estado. Clubes esportivos propagandeavam nos periódicos as vantagens das modalidades que ofereciam para o cultivo de corpos afeitos à moral do progresso. Enfatizavam o potencial eugênico e as benesses do esporte orientado para a construção de indivíduos fortes, laboriosos e disciplinados, portanto, úteis à pátria que se almejava construir.

Nesta perspectiva, o que se adjetivava como moderno se diferenciava de acordo com os corpos de homens e mulheres, em sintonia com as funções sociais destinadas a cada sexo. Dentre os esportes em que a participação feminina foi possível (como espectadora ou como atleta) nas primeiras décadas do século XX, pode-se destacar o atletismo. Sua prática foi comum em agremiações da capital e do interior, em clubes de elite e em clubes populares.

Na cidade de Barbacena, localizada na região mineira do Campo das Vertentes, cerca de 170 quilômetros de Belo Horizonte, a participação das mulheres nesse esporte, embora comportasse a possibilidade da prática competitiva, esteve bastante relacionada ao caráter décor citado por Souza Neto (2010).

Desse modo, o objetivo deste artigo é apresentar pistas sobre a participação das citadinas barbaceneses no atletismo, com o intuito de responder às seguintes questões: quem foram essas mulheres, como se inseriram na prática, quais sentidos e significados de sua participação.

Tais perguntas serão problematizadas por meio da análise de fontes periódicas, em específico o jornal Cidade de Barbacena. O impresso foi fundado em 1897 e extinto em 23 de janeiro de 1993. Pela sua periodicidade e diversidade de publicações é considerado o principal jornal da região (SAVASSI, 1991; RESENDE, 2012; RIBEIRO, 2012). Em suas páginas é possível ter contato com os hábitos citadinos, dentre eles a prática de esportes, seja no âmbito competitivo ou de lazer. As colunas Sociaes e Secção Sportiva apresentavam as programações de divertimentos da cidade, incluindo a agenda de sessões cinematográficas; apresentações teatrais; concertos musicais; festas religiosas, beneficentes, cívicas, de aniversário e núpcias; 
bailes dançantes e outras reuniões de clubes recreativos e literários, assim como de clubes esportivos.

O presente estudo é uma investigação inicial sobre a presença das mulheres no atletismo, parte de um esforço maior de mapear as práticas esportivas vivenciadas por elas na cidade. Especificamente para este texto, o recorte temporal é o ano de 1926, data da realização de um festival em comemoração ao aniversário de onze anos de fundação do Olympic Sport Club, que contou com provas de atletismo nas modalidades de velocidade, resistência, salto em altura, distância e obstáculos. Por meio desse festival é possível apreender parte do lugar ocupado pelas mulheres nas práticas esportivas da cidade.

\title{
Barbacena: breve contextualização da cidade
}

\begin{abstract}
Ha mulheres que, pela sua belleza e pelos seus encantos, exercem na gente uma influencia mysteriosa: basta que as contemplemos de relance para subitamente, por ellas nos apaixonarmos. Essa mysteriosa influencia que se observa no tocante das mulheres, nota-se tambem em relação ás cidades: quem vê Barbacena, sua incomparavel e magestosa natureza, seus morros de campinhas verdejantes e infinitas, este céo eternamente azul: quem priva com o seu povo bom, cavalheresco e insinuante; quem sente o frescor das brisas deliciosas que sopram os ventos desta terra, fica logo por ella apaixonada, e só póde deixal-a com um pedaço de sua'alma. Barbacena é uma terra que bole com o coração da gente, que faz vibrar intimamente a noss'alma, que inspira poesia, que infunde amor... (BRAGA, 1916, n. 1216, p. 1).
\end{abstract}

O trecho supracitado foi extraído do jornal Cidade de Barbacena e nele são ofertadas pistas de como a mulher era representada naquela sociedade. A comparação com a cidade se faz pela beleza e pelo encanto, características que se delineiam na escrita como inerentes ao feminino. Observa-se certa passividade na cidade/mulher, que está ali inerte, à espera de ser conquistada e vislumbrada pelos olhos de um desbravador apaixonado. A cultura esportiva das primeiras décadas do século XX é também fruto dessa estrutura de sentimentos (WILLIAMS, 2003).

As promessas da modernidade atravessaram o estado, assim como grande parte do país no final do século XIX, impactando sobremaneira a vida social. Barbacena era uma cidade de destaque em Minas Gerais no início do século XX, tendo em vista a dinâmica industrial e populacional da localidade (RIBEIRO, 2012). Conhecida pelos títulos de Cidade das rosas, Cidade da loucura e Cidade de embates políticos entre as famílias Bias Fortes e Andrada ${ }^{4}$ o

\footnotetext{
${ }^{4} \mathrm{O}$ título Cidade das rosas se dá por conta do cultivo e exportação de rosas e cravos da região para países europeus principalmente. Já Cidade dos loucos ou Cidade da loucura se refere pejorativamente às atividades do
} 
município neste recorte temporal também se distinguia pela produção de seda, frutas, vinho, derivados do leite, cerveja, fumo e cerâmica (RIBEIRO, 2012). Além disso, em razão das belezas naturais que constituem a cidade, Barbacena era também nomeada como a Princesa dos Campos (SAVASSI, 1991; MASSENA, 1985).

Entre os séculos XVIII e XIX, a região, enquanto Vila de Barbacena, obteve destaque econômico na Capitania de Minas devido a alguns fatores, como o privilégio geográfico entre as regiões auríferas mineiras e a Capital da República, na época a cidade do Rio de Janeiro, denominado Caminho Novo, o que permitiu a localidade se tornar ponto de comércio e hospedagem para autoridades e viajantes. O município também desenvolvia atividade agropecuária de exportação para o Rio de Janeiro, de queijo, toucinho, algodão, gado bovino, mulas, galinhas, e distribuía no estado mercadorias vindas da Europa, sobretudo de Portugal e da Inglaterra (TEIXEIRA, 2005).

A Vila de Barbacena foi elevada a cidade a partir da lei n. 163 de 9 de março de 1840, por ação do Deputado Joaquim Dias Bicalho, o qual afirmou que na região existia um grande número de sujeitos qualificados ao trabalho e a demais atividades que poderiam beneficiar a província mineira (SAVASSI, 1991).

Vale destacar que Barbacena foi uma das opções para ser a nova capital de Minas Gerais no final do século XIX, em substituição a Ouro Preto, disputando esse lugar com Juiz de Fora, Paraúna, Várzea do Marçal e Curral Del Rei. Esta última, antes uma vila, tornar-se-ia a futura capital Belo Horizonte. No entanto, mesmo com a proximidade geográfica à sede da República, o que poderia facilitar trocas econômicas entre o estado e o Rio de Janeiro, Barbacena foi eliminada da possibilidade de ser a sucessora de Ouro Preto, pois mesmo com potenciais ferroviários e lucros da lavoura cafeeira da região, a topografia foi considerada imprópria para o estabelecimento de mais de 50.000 pessoas (SILVEIRA, 2006).

Inúmeras mudanças na infraestrutura de Barbacena aconteceram em prol do ideário de modernidade propagado no início do século XX: ruas foram abertas e as vias centrais calçadas; reformas de edifícios e praças aconteceram a favor da instalação de uma estética moderna; mictórios foram instalados em ruas de grande movimento para promover a higiene; automóveis e auto-ônibus dividiram o espaço público com os citadinos e citadinas; indústrias alimentícias e têxteis foram inauguradas; a chegada da energia elétrica trouxe mais dinâmica à

Hospital Colônia na localidade, em que um grande contingente de pessoas em tratamento psiquiátrico foi exterminado. Por fim, a história da relação política nada amistosa entre as famílias Andrada e Bias Fortes pela disputa de poder local também caracteriza Barbacena como uma cidade de embates políticos. Para mais detalhes consultar: SAVASSI, 1991; MASSENA, 1985; RATTON, 1979; ARBEX, 2013. 
cidade, como, por exemplo, a frequência a salas de cinema e as sedes dos clubes recreativos e esportivos em programações noturnas, as soirées (SILVA, 2018).

Estudos anteriores identificaram que na cidade, até a década de 1930, existia a prática esportiva de ciclismo, boxe, tiro, corrida de cavalos, futebol, patinação e atletismo. Cita-se a Sub-Liga Queluziana de Desportos Terrestres, o Clube de Tiro, o clube de corrida de cavalos Derby Barbacenense, Olympic Football Club e Democrata Foot-ball Club como instituições responsáveis pela promoção de práticas esportivas na região (SAVASSI, 1991; SILVA, 2018; SILVA; ROSA, no prelo).

\section{Mulheres de Barbacena no atletismo}

As mulheres participaram, em especial, dos seguintes esportes e das seguintes formas: futebol, como assistentes-espectadoras e assistentes-torcedoras, responsáveis pelo lance inicial de jogos, pela entrega de premiação a equipes e como madrinhas de times (SILVA; ROSA, no prelo); no turfe, como assistentes; na patinação (SILVA, no prelo) e no atletismo, como competidoras. Em algumas práticas corporais como as danças modernas, mesmo que notícias veiculassem tentativas de interdição da presença das citadinas, a prática pelas mesmas acontecia (SILVA, no prelo). Já em outras, como escotismo e cavalhadas, a participação das mulheres se dava como Rainhas, granduquezas, Princesas e assistentes (SILVA, 2018).

A participação das barbacenenses no atletismo foi identificada em eventos de comemorações de aniversários do Olympic Football Club, agremiação existente na cidade desde 25 de julho de 1915, com sede definitiva no Morro de Santa Thereza a partir da década de 1920 (SILVA; ROSA, no prelo).

Em 1926, no aniversário de onze anos de fundação do Olympic foi organizado um festival comemorativo com dois principais momentos. No primeiro, os homens competiram em algumas modalidades atléticas, a citar as provas de velocidade, resistência, salto em altura e distância, ao passo que as mulheres participaram em específico da corrida com obstáculos. Já no segundo momento, aconteceu a partida de futebol entre o time local com o veterano de Belo Horizonte, o Athletico Mineiro, que saiu vencedor por 2 x 0 .

Conforme a fonte:

[...] Da primeira parte do programma constarão importantes competições athleticas e interessantes provas especialmente creadas para as gentilissimas $<<$ torcedoras $>>$, havendo para umas e outras bellissimos premios instituidos graciosamente pelos patronos das mesmas [...] (CALVO, 1926, n. 2213, p. 2). 
Percebe-se que as provas foram criadas para as torcedoras do time, que representavam as jovens locais, ao passo que para as mulheres de outras idades, como as senhoras, foi reservado o lugar de espectadoras:

[...] Realmente, aquella praça de sports apresentava encantador aspecto, comportando em suas vastas dependencias representantes de todas as classes, muitas senhoras e elevado numero de graciosas $\langle<$ torcedoras $\rangle>$.

Da primeira parte do programma, dirigida pessoalmente pelo devotado <<sportman>> Sr. Emmanoel Taveira, esforçado presidente do nosso sympathico gremio desportivo, constaram bellas provas de athletismo que evidenciaram a pujança physica da nossa mocidade. Dellas destacamos, em menção especial, a carreira de velocidade, brilhantemente vencida por Geraldo Brasil; a de resistencia por José Chedid, que bateu Rosalvo na recta final em estupenda chegada e demonstrando apreciavel folego; as de salto em altura e distancia a que registraram duas magnificas victorias do arrojado Edson Cintra Vidal.

Constituiram a nota mais interessante do festival as corridas com obstaculos, dos quaes compartilharam graciosamente as alegres e elegantes $<<$ torcedoras $>>$. Venceram nelas as senhorinhas Aracy Esteves, Clydéa Tavares, Lynce e Sevigné Henriques e Daura Rodrigues.

Aos vencedores foram entregues, em seguida, os bellos premios offerecidos pelos patronos das provas, recebendo-os aquelles das mãos da gentil senhorinha Iracema Pereira da Silva que é madrinha do segundo team official do <<Olympic〉> [...]. (CALVO, 1926, n. 2216, p. 2).

Distintas modalidades foram destinadas aos homens e às torcedoras no ano de 1926, porém, somente as competições dos homens "evidenciaram a pujança physica da nossa mocidade" (CALVO, 1926, n. 2216, p. 2). O foco na preparação de um corpo masculino forte estava atrelado a uma das necessidades da modernidade, a regeneração física em prol do desenvolvimento da raça. Aos homens jovens desejava-se um corpo vigoroso que se transformasse em útil para servir à nação e representá-la.

Já para as mulheres, a modernidade apregoada pelos esportes esteve atrelada à preocupação com suas funções de esposa e mãe, especialmente na preparação do corpo para a gestação. Por essa razão, nem todas as modalidades praticadas pelos homens eram indicadas para as mulheres, que deveriam preservar suas características feminis de graça, elegância e gentileza, para a manutenção do desejo de seus maridos e representação de seu sexo na sociedade (GOELLNER, 1999; SANTA’ANNA, 2014).

Ao encontro dessas preocupações, as provas de atletismo destinadas às mulheres, no festival de 1926, diferenciavam-se das dos homens. Enquanto eles competiam nas provas de velocidade, resistência, salto em altura e distância, as torcedoras participavam exclusivamente da corrida de obstáculos, pois essa modalidade não comprometia as características de graciosidade, alegria e elegância, tão custosas a representação de seu sexo neste marco 
temporal. Em outras palavras, o atletismo foi um esporte autorizado às mulheres, porém, reduzido em suas possibilidades, o que pode se relacionar aos intentos de preservação de características e comportamentos desejados. Já os homens poderiam se envolver em mais de uma modalidade, pois a virilidade relacionada ao sexo masculino se potencializava com o envolvimento em competições esportivas variadas.

Ainda sobre a referida comemoração, destaca-se que foi noticiada a presença de representantes de todas as classes, o que pode sugerir que abastados e populares compareceram nesta festividade. Contudo, em se tratando das mulheres que competiram no atletismo algumas pistas dizem de uma das participantes: Aracy Esteves. Dado o caráter secundário ou decorativo posto na imagem feminina nos eventos de atletismo, com explícita preocupação com características como a graciosidade, beleza e elegância supõe-se que a participação em festivais como o de 1926 estava mais voltada a jovens com relevante representatividade social.

Aracy Esteves foi uma mulher de destaque no meio social barbacenense. Quando criança estava entre as eleitas para a coroação de Nossa Senhora, referente à comemoração do mês de Maria na Igreja da Boa Morte (MOVIMENTO RELIGIOSO, 1915, n. 1127, p. 1). Em 1926, mesmo ano em que competiu na prova de obstáculos, organizou junto a outras senhorinhas locais um sarau dançante dedicado ao ilustre Sr. Dr. Bias Fortes, Secretário da Assistência e Segurança Pública, denominado de Festa do Bem-me-quer no Club Barbacenense (FESTA DO BEM-ME-QUER, 1926, n. 2253, p. 1), associação da elite local (SILVA, 2018).

No ano seguinte, 1927, Aracy Esteves amadrinhou um dos times de futebol que competiram no Campeonato Interno promovido pelo Olympic Futebol

Club denominado Torneio Initium:

Foot-ball

Terá inicio hoje o campeonato interno do "Olympic Club", devendo ser o primeiro jogo disputado às 9 horas

A directoria do Olympic organizou um interessante Campeonato Interno, que terá inicio hoje com o <<Torneio Initium >>.

Estão organizados quatro teams, cujas forças parecem bem equilibradas.

Team senhorinha Aracy Esteves

Carlinhos - Dario - Ninico - Odilon - Cyro - Lima - Vianna - Sinhô -

Celso - Gastão - Waldemar

Capitão - Cyro Duque Estrada

Team senhorinha Celia de Queiroz.

Ernesto - Affonso - Telinho - Waldemar - Domingos - Malta - Lauro Totó - Tatão - Arlindo - Chedid 
Capitão - Sebastião Ribeiro Mendes (Tatão)

Team senhorinha Yáyá Moreira

Brasil - Mozart - Synval - Lulú - Mario - Fabio - Argentino - Garizo Cecy - Leopoldo - Lopes

Capitão - Mario F. Gomes

Team senhorinha Carmen Fontana Paulucci

Paulo - Claudio - Lindolpho - Mazico - Orestes - Orpheu - Ary - Sandico

- Guilherme - Betinho - Geraldo

Capitão - Guilherme Menezes

O $<<$ Torneio $>$ terá inicio ás 9 horas, devendo obedecer ao seguinte programma:

$1^{\circ} \mathrm{JOGO}$

Celia de Queiroz e Yaya Moreira

$2^{\circ} \mathrm{JOGO}$

Aracy Esteves e Carmen Paulucci

$3^{\circ} \mathrm{JOGO}$

Vencedor do $1^{\circ} x$ Vencedor do $2^{\circ}$

Os juizes serão escolhidos pelos captains dos teams dos disputantes. Os captains dos quatro teams concurrentes, constituirão o Conselho Divisional, cujas decisões estarão sempre sujeitas à aprovação da Directoria do Olympic Club, que terá as funcções de Conselho Superior.

O ingresso no campo, tanto para o Torneio como para os matchs de <<Campeonato〉> será gratuito (CALVO, 1927, n. 2335, p. 2).

O time Celi Queiroz venceu o Torneio Initium de 1927, e a equipe de Aracy Esteves foi a vice-campeã (CALVO, 1927, n. 2337, p.2).

A prática de futebol por mulheres em Barbacena não foi identificada nos anos estudados, contudo, o time de futebol do Olympic Sport Club foi o responsável pela oferta de provas de atletismo ao bello sexo em festividades de comemorações de seus aniversários de onze e quatorze anos. Ao que sugerem as fontes, o atletismo não era visto como ameaça ao corpo feminino, ao passo que esportes com características entendidas como viris eram desaconselhadas ou negadas. Nesse caso, às mulheres era relegado o lugar de representantes dos times, de ornamento ou decoração, haja vista que eram destacadas no jornal pela graciosidade de seus corpos. Mesmo quando participaram do evento de atletismo como competidoras, o destaque conferido a elas se direcionava a caracteres estéticos, ao contrário dos homens, noticiados por suas habilidades físicas. 


\section{Considerações finais}

Neste artigo foi analisada a participação das mulheres em um evento de atletismo realizado em 1926, quando o Olympic Sport Club comemorou seu décimo primeiro aniversário. Contudo, em 1929, uma festividade organizada com o mesmo fim celebrativo incluiu provas atléticas para as torcedoras (CALVO, 1929, n. 2511, p. 2), todavia ainda não foram identificados demais detalhes na fonte de estudo. Para tanto, é necessário investigar outros documentos.

Mulheres jovens e que já participavam como torcedoras do time do Olympic Sport Club foram as participantes das prova atléticas de obstáculos em 1926.

Dos sentidos e significados, pode-se interpretar que o caráter "décor" sugerido por Souza Neto (2010) foi prevalente. Entretanto, mesmo em via de fomentos e inibições, o fato de mulheres participarem de provas atléticas em espaços em que se privilegiava a prática de homens, tanto no atletismo quanto no futebol, diz de emancipação, ou seja, superação de barreiras sociais dentro da história do esporte pensadas para o sexo feminino.

Novas análises precisam ser acrescentadas à história dos esportes de Barbacena, assim como à história das citadinas nas diferentes modalidades. Por fim, este artigo mesmo em estágio inicial corrobora a reflexão de que ainda existem muitas mulheres invisibilizadas na história dos esportes. Como exemplo, podem ser citadas as atletas Irenice Maria Rodrigues, Wanda dos Santos e Aída dos Santos, dentre tantas outras que tiveram importante contribuição para o atletismo brasileiro e ainda figuram de maneira secundária no âmbito acadêmico.

\section{Referências bibliográficas}

ARBEX, D. O holocausto brasileiro: vida, genocídio e 60 mil mortes no maior hospício do Brasil. São Paulo: Geração Editorial, 2013, 272 p.

BRAGA, T. Cidade de Barbacena, Barbacena, 16 abril 1916, n.1216, p. 1.

BRASIL. Conselho Nacional de Desportos, Decreto-Lei n. 3.199 de 14 de abril de 1941. Disponível em: .http://www.planalto.gov.br/ccivil_03/Decreto-Lei/1937-1946/Del3199.htm Acesso em 28 fev. 2020.

CALVO. Cidade de Barbacena, Barbacena, 22 jul. 1926, n. 2213, p.2.

CALVO. Cidade de Barbacena, Barbacena, 1 ago. 1926, n. 2216, p.2.

CALVO. Secção sportiva, Cidade de Barbacena, Barbacena, 16 out.1927, n. 2337, p.2.

CALVO. Secção Sportiva. Cidade de Barbacena, Barbacena, 16 out. 1927, n. 2337, p.2.

CALVO. Cidade de Barbacena, Barbacena, 6 jul. 1929, n. 2511, p.2. 
FERREIRA, José Cipriano Soares. Resumo histórico do município de Barbacena - Sinopse estatística do município de Barbacena. In: DEPARTAMENTO ESTADUAL DE ESTATÍSTICA. 1948. p. 16-18.

FESTA DO BEM-ME-QUER. Cidade de Barbacena, Barbacena, 12 dez. 1926, n. 2253, p. 1. GOELLNER, S. V. Bela, maternal e feminina: imagens da mulher na Revista Educação Physica. 1999. 194 f. Tese (Doutorado) - Faculdade de Educação, Universidade Estadual de Campinas, Campinas, 1999.

MALUF, M.; MOTT, M. L. Recônditos do mundo feminino. In: SEVCENKO, N. História da vida privada no Brasil. São Paulo: Companhia das Letras, 1998. v. 3. p. 368-421.

MELO, V. A. Trânsitos culturais: as experiências dos primeiros clubes athleticos do Rio de Janeiro (1873-1883). Movimento, Porto Alegre, v. 25, 2019, p. 1-13.

MASSENA, Nestor. Barbacena: a terra e o homem. v. 1, Belo Horizonte: Imprensa

Oficial, 1985.

MELO, V. A. O corpo esportivo nas searas tupiniquins - um panorama histórico. In: AMANTINO, M.; DEL PRIORE, M. (Orgs.). História do corpo no Brasil. São Paulo: Editora da Unesp, 2011. p. 123-145.

MELO, V. A. Os sports e as cidades brasileiras: transição dos séculos XIX e XX. Rio de Janeiro: Apicuri, 2010.

MELO, V. A. Corpos, bicicletas e automóveis: outros esportes na transição dos séculos XIX e XX. In: DEL PRIORE, M.; MELO, V. A. História do esporte no Brasil: do império aos dias atuais. São Paulo: UNESP, 2009, p. 71-105.

MELO, V. A. Mulheres em movimento: a presença feminina nos primórdios do esporte na cidade do Rio de Janeiro (até 1910). Revista Brasileira de História, São Paulo, v. 27, n. 54, 2007, p. 127-152.

MOVIMENTO RELIGIOSO. Cidade de Barbacena, Barbacena, 30 maio 1915, n. 1127, p. 1. OLIVEIRA, G. A. S.; COSTA, J. S. Atletismo feminino nos Jogos Olímpicos. In: DA COSTA, L. (ORG.). Atlas do esporte no Brasil. Rio de Janeiro: CONFEF, 2006, p. 8250.

PIACESI, I. Crepusculos de Barbacena. Nação brasileira, ano II, n. 16, dezembro de 1924, p.77. Disponível em: http://memoria.bn.br/DOCREADER/cache/5212509709284/I000093120Alt=002316Lar=001672LargOri=002658AltOri=003681.JPG Acesso em 13 fev. 2020.

PIMENTA, E. F. Duas faces de uma mesma moeda: recepção e circulação do ideário fascista e integralista em Barbacena-MG através do casal Ines e Aroldo Piacesi, 1924-1945. 2015. 262 f. Dissertação (mestrado), Universidade Federal de São João Del Rei-MG, 2015.

PIMENTA, E. F. Ines Piacesi, 1895, 1981: um ensaio biográfico. 2007. 110 f. Monografia (bacharelado em História), Universidade Federal de Ouro Preto, Mariana -MG, 2007.

RATTON, H. Em nome da razão [Documentário]. Grupo Novo de Cinema e Associação Mineira de Saúde Mental, out. 1979. Disponível em: https://vimeo.com/162724580. Acesso em: 15 mar. 2020.

RESENDE, Edna Maria. Do debate político à notícia: a imprensa periódica em Barbacena séculos XIX e XX. Revista Mal-Estar e Sociedade, Barbacena, ano V, n. 8, jan.-jun., 2012, p.15-40.

RIBEIRO, J. S. História Econômica do Município de Barbacena v.1 (1889-1930) - Tempos de Esperança/Silvério Ribeiro)/ Barbacena: Gráfica e Editora Cidade de Barbacena, 2012, 704 p.

SANT'ANNA, D. B. História da beleza no Brasil. São Paulo: Editora Contexto, 2014. 205 p. SAVASSI, A. J. Barbacena 200 anos. Belo Horizonte: Editora Lemi S.A, 1991. v. 1. 287 p.

SCHPUN, M. R. Códigos sexuados e vida urbana: as práticas esportivas da oligarquia paulista nos anos vinte. In: SCHPUN, M. R. (Org.). Gênero sem fronteiras: oito olhares sobre mulheres e relações de gênero. Florianópolis: Editora Mulheres, 1997. p. 43-71. 
SEVCENKO, N. Transformações da linguagem e advento da cultura modernista no Brasil. Estudos Históricos, Rio de Janeiro, vol.6, n.11, 1993, pp. 78-88.

SILVA, I. M. Da participação das mulheres nas danças em Barbacena - MG (Cidade de Barbacena, 1915-1930). Recorde: Revista de História do Esporte, Rio de Janeiro, no prelo.

SILVA, I. M. "Rápida como os patins": a presença das mulheres na patinação em BarbacenaMG no início do século XX. Recorde: Revista de História do Esporte, Rio de Janeiro, no prelo.

SILVA, I. M; ROSA, M. C. Da participação de mulheres no futebol em Barbacena/MG nas três primeiras décadas do século XX. Revista Licere, no prelo.

SILVA, I. M. Elas se divertem (Barbacena - MG, 1914 a 1931). 2018. 136 f. Dissertação (Mestrado) - Escola de Educação Física, Fisioterapia e Terapia Ocupacional, Universidade Federal de Minas Gerais, Belo Horizonte, 2018.

SILVEIRA, A. J. T. Entre Febres, papudos e brejais: a mudança da capital mineira sob a ótica da higiene. In: CONDÉ, M. L. L. Ciência e cultura na história, Brasília, DF: CAPES, Belo Horizonte, MG: Argvmentvm, 2006, p. 39-60.

SOUTTO MAYOR, S. T. O futebol na cidade de Belo Horizonte: amadorismo e profissionalismo nas décadas de 1930 e 1940. 2017. 359 p. Tese (Doutorado em Estudos do Lazer) - Escola de Educação Física, Fisioterapia e Terapia Ocupacional, Universidade Federal de Minas Gerais, Belo Horizonte, 2017.

SOUZA NETO, G. J. A invenção do torcer em Belo Horizonte: da assistência ao pertencimento clubístico (1904-1930). 2010. 130 f. Dissertação (Mestrado) - Escola de Educação Física, Fisioterapia e Terapia Ocupacional, Universidade Federal de Minas Gerais, Belo Horizonte, 2010.

TEIXEIRA, A. B. Viajando pela Vila de Barbacena: possibilidades de história regional para Minas oitocentista sob o olhar dos viajantes. In: SIMPÓSIO NACIONAL DE HISTÓRIA: ANPUH, 23, Londrina, 2005. Anais..., Paraná, 2005, p. 1-8.

WILLIAMS, R. La larga revolución. Buenos Aires: Nueva Vision, 2003. 